\title{
Evaluation of Sleep Habits, Generalized Anxiety, Perceived Stress, and Research Outputs Among Postgraduate Research Students in Hong Kong During the Coronavirus (COVID-19) Pandemic
}

\author{
Shahnawaz Anwer (iD) 1,2 \\ Heng Li (D) ${ }^{2}$ \\ Maxwell Fordjour Antwi- \\ Afari iD $^{3}$ \\ Mohammad Abu Shaphe (D) ${ }^{4}$ \\ Ahmad Alghadir' \\ Arnold YL Wong (D)

\begin{abstract}
'Rehabilitation Research Chair, College of Applied Medical Science, King Saud University, Riyadh, Saudi Arabia;

${ }^{2}$ Department of Building and Real Estate, Faculty of Construction and Environment, Hong Kong Polytechnic University, Kowloon, Hong Kong Special Administrative Region; ${ }^{3}$ Department of Civil Engineering, College of Engineering and Physical Sciences, Aston University, Birmingham, B4 7ET, UK; ${ }^{4}$ Department of Physical Therapy, College of Applied Medical Sciences, Jazan University, Jazan, Saudi Arabia; ${ }^{5}$ Department of Rehabilitation Sciences, The Hong Kong Polytechnic University, Kowloon, Hong Kong Special Administrative Region
\end{abstract}

Correspondence: Shahnawaz Anwer Email Shahnawaz.anwer@connect.polyu.hk
Purpose: The current study aimed to evaluate the impact of coronavirus (COVID-19) pandemic on sleep hygiene, anxiety levels, perceived stress, and research output among postgraduate research students in Hong Kong.

Methods: An online survey was developed and distributed to Hong Kong postgraduate research students. The sleep hygiene, anxiety levels, and perceived stress during the outbreak of COVID19 were assessed. Questions about COVID-19's impact on research outputs were asked.

Results: A total of 108 (response rate, 72\%) full-time postgraduate students (PhD, 64\%; M Phil, $8 \%$; and Masters, 28\%) participated. Approximately $83 \%$ of students reported poor sleep hygiene. Similarly, nearly $76 \%$ of students reported mild to severe levels of self-perceived anxiety levels. Most of the respondents (89\%) expressed a moderate level of perceived stress. Sleep hygiene scores were moderately associated with anxiety levels $(r=0.384, p<0.01)$ and perceived stress scores $(r=0.423, p<0.01)$. Perceived stress was strongly correlated with anxiety levels $(\mathrm{r}=0.601, \mathrm{p}<0.01)$. A hierarchical regression analysis revealed a significant association between respondents' ethnicity $(B=-0.923, p=0.003)$, past medical history (such as hypertension, diabetes, and musculoskeletal disorders $)(B=1.112, p=0.005)$, or poor sleep hygiene $(\mathrm{B}=0.259, \mathrm{p}=0.000)$ and high levels of perceived stress. Additionally, prior medical history (such as hypertension, diabetes, and musculoskeletal disorders) $(\mathrm{B}=1.957, \mathrm{p}=0.001$ ) and poor sleep hygiene $(\mathrm{B}=0.312, \mathrm{p}=0.000)$ were found to be strongly related to anxiety levels among postgraduate research students.

Conclusion: This is the first study that highlights poor sleep hygiene, moderate-to-severe levels of anxiety, and perceived stress during the COVID-19 pandemic in postgraduate research students in Hong Kong. These findings will help educators to prepare strategies to alleviate the stress and psychological problems in postgraduate students.

Keywords: coronavirus, COVID-19 pandemic, postgraduate students, research, anxiety, sleep hygiene, stress

\section{Introduction}

Coronavirus disease 2019 (COVID-19) has been declared as a pandemic and a public health emergency by the World Health Organization (WHO) on January 30, 2020. ${ }^{1}$ Approximately, 223 countries and territories have been affected by the COVID-19 pandemic worldwide. ${ }^{2}$ As of June 9, 2021, more than 173 million people have contracted the new coronavirus and over 3.7 million people died from COVID-19 globally. ${ }^{2}$ To prevent the spread of the new coronavirus, ie, severe acute 
respiratory syndrome (SARS-CoV-2), many countries have adopted multiple containment measures including a ban of mass gatherings, social distancing, closure of educational institutions, religious centers, community centers, amusement parks, and shopping malls. ${ }^{3}$ Similarly, Hong Kong has also implemented these containment measures to prevent the spread of the virus and to flatten the curve. ${ }^{4,5}$ Although Hong Kong has a population of approximately 7.5 million, it successfully kept the number of confirmed cases and death tolls to 11,873 and 210 , respectively, as of June $9,2021 .^{2}$ However, due to the suspension of academic activities, public parks, and fitness centers, the physical, mental, and social wellbeing of all levels of students may have been greatly impacted. In particular, postgraduate research students are not allowed to carry out their day-to-day research activities (eg, experiments), which may inevitably affect their research outputs. ${ }^{6}$ While the COVID-19 pandemic has caused suspension of life globally, research students may be one of the most affected communities among others. ${ }^{7}$ A recent survey on the impacts of the COVID-19 outbreak on 424 universities and other higher education institutions from 111 countries and territories found that about $80 \%$ of higher education institutions reported their research activities being negatively impacted by the COVID-19 pandemic. ${ }^{8}$ The most commonly impacted activities were cancellation of foreign travels ( $83 \%$ of participating institutions), cancellation of research conferences ( $81 \%$ of participating institutions), and missing the proposed completion deadline of research projects $(52 \%$ of the participating institutions). Since the academic journey of postgraduate research students cannot be stopped due to the COVID-19 pandemic, ${ }^{9}$ they are at risk of developing a poor sleep habit (eg, wake up late and stay up late; consumption of alcohol, tobacco, or caffeine at bedtime; or playing video games; use of internet or watching television at bedtime) and worrying about their academic performance in an adverse condition.

Sleep is important for physical and mental health, as well as cognitive function. ${ }^{10,11}$ Poor sleep can negatively impact academic performance, ${ }^{12}$ while sufficient sleep can boost immunity and help fight against stress and other infections. ${ }^{13}$ Poor sleep quality is known to be associated with behavioral and environmental factors (such as poor sleep habits, also known as sleep hygiene). ${ }^{14}$ Sleep hygiene refers to habits, daily practices, and environmental factors (eg, cold, hot, or bright bedrooms) that are vital for improving sleep quality at night. ${ }^{15}$ Although the impacts of sleep hygiene on sleep quality in university students have not been examined, sleep hygiene is one of the most important variables that needs to be checked among individuals with poor sleep quality. ${ }^{16}$ While sleep hygiene behaviors can potentially affect sleep quality, poor sleep hygiene is detrimental to sleep. ${ }^{17}$ Many behaviors and environmental factors (eg, avoiding caffeine, alcohol, and nicotine at bedtime; avoiding daytime naps; adherence to regular sleep and wake time; keeping a bedroom neat and clean; and avoiding television watching or smartphone usage at bedtime) are considered as proper sleep hygiene that may promote the quality of sleep. ${ }^{17}$

Since sleep hygiene is one of the important factors affecting sleep quality and quantity, some studies have examined sleep hygiene behaviors among college and university students. ${ }^{18-20}$ Poor sleep hygiene not only is associated with poor academic performance $e^{21-23}$ but also in university students who had a history of anxiety, ${ }^{24,25}$ and stress. ${ }^{26}$ While some studies identified generalized anxiety as one of the risk factors for poor sleep hygiene among university students and the general population, ${ }^{27,28}$ others suggested a bidirectional relationship between generalized anxiety and depression and poor sleep hygiene among the general population. ${ }^{29,30}$ Furthermore, significant associations were noted between generalized anxiety and sleep quality or excessive daytime sleepiness in university students. ${ }^{31}$

Postgraduate research students are known to experience multiple sources of anxiety or perceived stress (eg, deadlines to complete various projects, publication demands, course work requirements, and thesis submissions). ${ }^{32,33}$ Additionally, increased exposure to television has been observed to have a detrimental effect on mental health during the pandemic. ${ }^{34}$ However, there is limited relevant research regarding sleep hygiene, anxiety levels, and perceived stress among postgraduate research students during the COVID-19 pandemic. Additionally, the fear of getting infected with COVID-19 may increase stress and anxiety. Furthermore, COVID-19 may lead to a lack of daily routine (eg, going to campus to conduct experiments) that may cause research students to stay up late at night to play games or to study, which may affect sleep hygiene and overall research output of postgraduate research students. Therefore, this study aimed to evaluate the impact of the COVID-19 pandemic on sleep habits, anxiety levels, perceived stress, and research outcomes among postgraduate students studying in Hong Kong. The findings may help design effective prevention or 
management strategies to minimize the negative effects of COVID-19 on postgraduate research students.

\section{Materials and Methods}

An online self-administered questionnaire was developed using the validated sleep hygiene index (SHI), ${ }^{35}$ generalized anxiety disorder (GAD-7) index, ${ }^{36}$ and perceived stress scale (PSS-10). ${ }^{37}$ Full-time postgraduate research students including $\mathrm{PhD}$, MPhil, and masters aged 18 years or older were invited to participate in the survey. This research project was approved by the Human Subjects Ethics Sub-committee of The Hong Kong Polytechnic University (Reference number: HSEARS20200616004). The online questionnaire was divided into five screen pages: (1) 11 questions related to socio-demographics; (2) 13 questions related to sleep hygiene during the pandemic (a component of SHI); (3) 7 questions related to anxiety levels during the pandemic (a component of GAD index); (4) 10 questions related to selfperceived stress during the pandemic (a component of PSS10 scale); and (5) 6 questions related to the impacts of COVID-19 on research outputs. Additionally, participants were asked to report their major concerns during the COVID-19 pandemic. An English questionnaire was used. The survey was developed using the Typeform (C) survey platform, which has been used in similar previous studies. $^{38,39}$ This survey took approximately 15 minutes to complete. A browser cookie was used to prevent respondents from repeating the survey in the same browser. No monetary incentives were offered to participants, but there was link to a website that offer COVID-19 information (eg, the World Health Organization website) and telephone numbers for seeking assistance, support, or more information. An invitation email with the hyperlink to the online survey was sent to the research offices of 8 government-aided universities in Hong Kong. They were requested to forward the email to all their postgraduate research students to invite their participation. The participant would automatically give their implied consent to participate if they accepted the invitation and submitted their questionnaire. Participation was voluntary and participants could quit at any time even after they had started (Figure 1). This study was carried out in compliance with the Helsinki Declaration's guidelines.

The data was collected between 18th June 2020 and 18th August 2020, during which the Hong Kong government declared a state of health emergency for COVID-19. In particular, the Hong Kong government implemented a number of containment measures, including a prohibition on group gatherings, social segregation, as well as the closure of educational institutions, religious centers, community centers, amusement parks, and shopping malls. Additionally, the government offered free COVID-19 testing to the general public via a variety of channels. Asymptomatic individuals who were suspected to be at a higher risk of exposure would obtain free test kits at designated public clinics or other distribution points. Individuals required to take mandatory tests should visit community testing centers for free testing. Additionally, these centers offered self-pay services to those who required test reports for personal use. As a result, the majority of students were confined to their dormitory or home at the time of our data collection of this research and were not permitted to visit the university campus for their research activities.

\section{Descriptions of SHI, GAD-7, and PSS- 10 Questionnaires \\ $\mathrm{SHI}$}

The SHI is a 13-item questionnaire, which was developed to evaluate sleep hygiene during a routine day-to-day life. ${ }^{35}$ The International Classification of Sleep Disorders (ICSD-2; American Academy of Sleep Medicine) has classified sleep hygiene behaviors into five categories: (1) improper sleep wake-up cycle (eg, napping, irregular bed and wake times); (2) the use of sleep affecting substances (eg, caffeine, nicotine, and alcohol); (3) behaviors that boost arousal at bedtime (eg, engaging in emotional or exciting activities); (4) use of the bedroom other than sleep (eg, reading, watching television); and (5) unable to sustain a pleasant sleeping environment (eg, distressing temperature or mattress). Individuals were asked to indicate if they engaged in specific sleep hygiene behaviors. ${ }^{40}$ A 5-point Likert scale in which ' 0 ' indicating "never" and '4' indicating 'always' was used for the scoring. The final SHI score (ranging between 0 and 52) was calculated by summing all item scores. A higher SHI score indicates poorer sleep hygiene behavior. The SHI has shown acceptable reliability (Cronbach's $\alpha=0.66$; McDonald's Omega $=0.76$ ) and validity in different populations (including university students). ${ }^{35,41}$

\section{GAD-7}

The GAD-7 is a 7-item questionnaire designed to assess the magnitude of generalized anxiety symptoms as described in the Diagnostic and Statistical Manual of Mental Disorders-IV. ${ }^{35}$ It is graded on a 5-point Likert scale, where ' 0 ' indicates "not at all" and ' 4 ' implies 


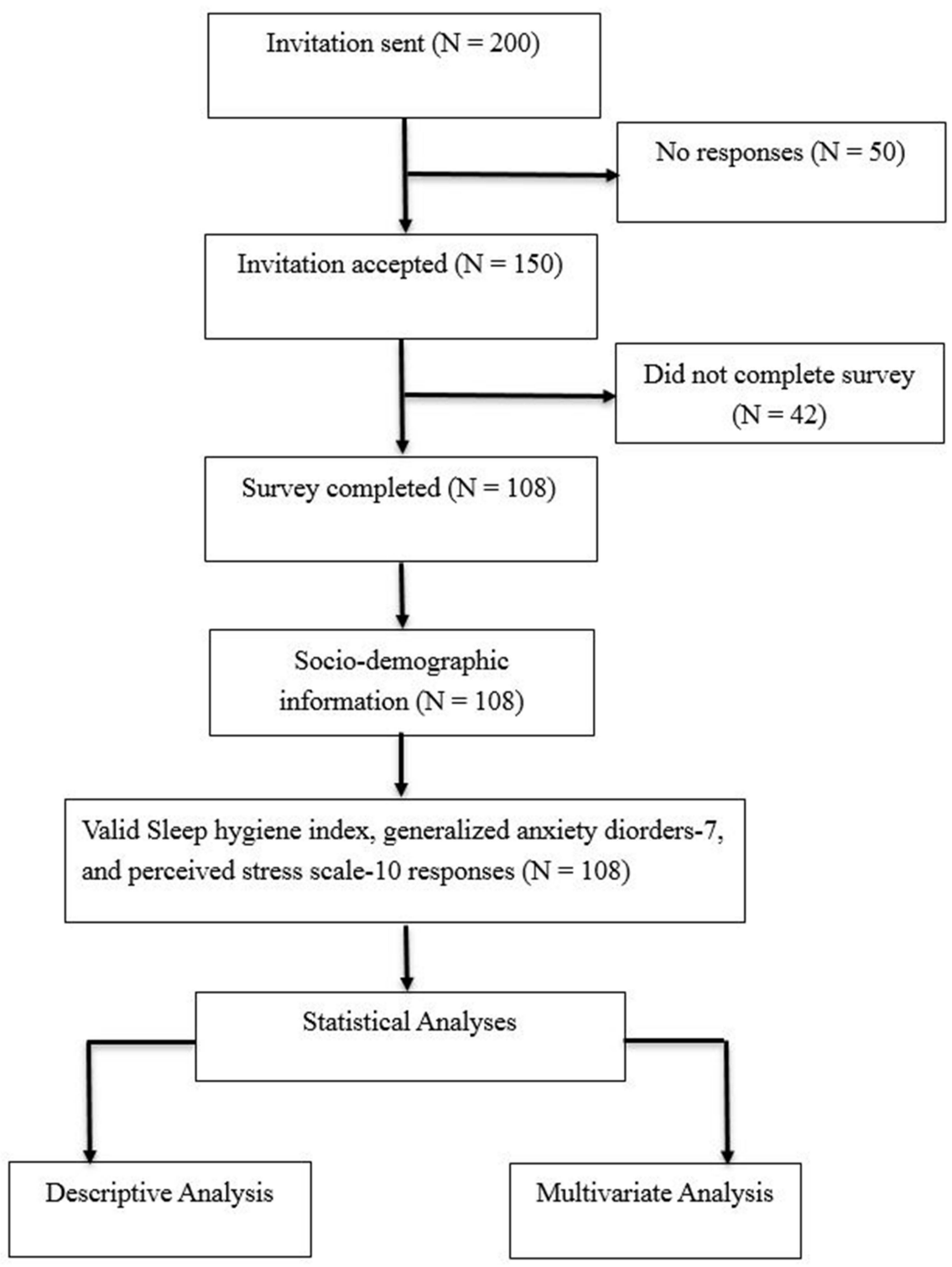

Figure I Flow chart of survey process.

'nearly every day'. The final GAD-7 score was calculated by adding all items (a maximum of 28). The GAD-7 has adequate reliability (Cronbach's alpha $=0.83$ ) and validity in multiple populations including university students. ${ }^{42,43}$

\section{PSS- 10}

The PSS-10 is a 10-item questionnaire designed to evaluate the levels of self-perceived stress. ${ }^{36}$ Each item is graded on a 5-point Likert scale indicating "never" (0 scores) and "very often" (4 points). PSS score ranges from 0 to 40 . The final PSS score was calculated by reversing the responses of positively stated questions $4,5,7$, and $8(\mathrm{eg}, 0=4,1=3$, $2=2,3=1$ and $4=0$ ) and then adding the scores of all items. $^{36}$ Greater scores mean higher levels of stress.
Previous studies found an adequate internal consistency (McDonald's Omega $=0.68$ to 0.80 ) of PSS-10.44,45

\section{Data Analysis}

Data were analyzed using the statistical package for social sciences (SPSS, Windows version 22, IBM, USA). Pearson correlations coefficients were used to evaluate the bivariate correlations among SHI, anxiety levels, and PSS scores during the COVID-19 pandemic. Separate hierarchical regression models were used to identify independent determinants for anxiety levels and perceived stress scores. In these models, age, sex, marital status, and ethnicity were entered at the first regression step. Accommodation, level of education, and field of research were then entered as the second step in the anxiety 
levels and perceived stress models. Past medical history, country of stay during the outbreak of COVID 19, and sleep hygiene scores were subsequently entered at the third step. ${ }^{46}$ The strengths of associations were estimated by the beta coefficient. Additionally, effect sizes of regression analyses (ie, Cohen's $\mathrm{f}^{2}$ ) were calculated using an $\mathrm{R}^{2}$ value to identify clinically significant associated factors. ${ }^{47}$ Twenty-four (16\%) respondents were excluded because their responses had missing data in any variable. An online sample size calculator was used to estimate sample size (https://www.danielsoper.com/ statcalc/default.aspx), which revealed that 105 individuals were required to detect a medium effect size $\left(f^{2}=0.17\right)$. This was calculated based on a linear regression model with 10 independent variables under the assumption of 0.80 statistical power and an alpha level of 0.05 . Data were considered statistically significant if $\mathrm{p}<0.05$.

\section{Results}

\section{Socio-Demographics}

One-hundred-eight respondents completed the survey (response rate, $72 \%$ ). Table 1 details the respondents' sociodemographic data. Nearly two-thirds $(n=68,63 \%)$ of the respondents were males. More than half $(n=59,55 \%)$ of the respondents were unmarried. Approximately one-third $(\mathrm{n}=39,36 \%)$ of the respondents were living in a rented room. The respondents were mainly Indians $(\mathrm{n}=37,34 \%)$, Chinese/Hongkongers $(\mathrm{n}=30,28 \%)$, and African natives $(\mathrm{n}=28,26 \%)$. More than $66 \%$ of the respondents had no past medical history. Approximately $10 \%$ of the respondents reported a history of systemic illness (eg, high blood pressure, diabetes mellitus, etc.). Nearly one-third of the respondents reported that they have stayed in Hong Kong during the outbreak of COVID-19 pandemic. Majority of the respondents were currently studying $\mathrm{PhD}$ students $(>50 \%)$. They were studied in the allied health $(33 \%)$, medical $(14 \%)$ or social science (12\%), and engineering (30\%) fields.

\section{Sleep Hygiene, Generalized Anxiety, and Perceived Stress Scores During the COVID- 19 Pandemic}

Sleep habits, perceived anxiety, and perceived stress of postgraduate research students were high during the COVID-19 pandemic (Table 2). The SHI, GAD-7, and PSS-10 scores were 23.1 (SD, 7.3), 9.2 (SD, 6.2), and 21.3 (SD, 4.3),
Table I Demographics of Respondents

\begin{tabular}{|c|c|}
\hline Variables $(N=108)$ & Frequency (\%) \\
\hline \multicolumn{2}{|l|}{ Age (Years) } \\
\hline Mean (Standard deviation) & $30.6(4.8)$ \\
\hline$\leq 25$ & $20(18.5)$ \\
\hline $26-30$ & $46(42.6)$ \\
\hline $31-35$ & $24(22.2)$ \\
\hline$\geq 36$ & $18(16.7)$ \\
\hline \multicolumn{2}{|l|}{ Gender } \\
\hline Male & $68(63)$ \\
\hline Female & $40(37)$ \\
\hline Other & $0(0)$ \\
\hline \multicolumn{2}{|l|}{ Marital status } \\
\hline Unmarried & $59(54.6)$ \\
\hline Married & $49(45.4)$ \\
\hline Other & $0(0)$ \\
\hline \multicolumn{2}{|l|}{ Ethnicity } \\
\hline Indian & $37(34.3)$ \\
\hline Chinese/Hongkongers & $30(27.7)$ \\
\hline African & $28(25.9)$ \\
\hline Arab & $8(7.4)$ \\
\hline Others & $5(4.6)$ \\
\hline \multicolumn{2}{|l|}{ Level of pursuing education } \\
\hline $\mathrm{PhD}$ & $69(63.9)$ \\
\hline M. Phil & $9(8.3)$ \\
\hline Masters & $30(27.8)$ \\
\hline \multicolumn{2}{|l|}{ Fields of research } \\
\hline Engineering & $32(29.6)$ \\
\hline Medical & $15(13.9)$ \\
\hline Allied Health & $36(33.3)$ \\
\hline Social Sciences & $13(12.0)$ \\
\hline Others & $12(11.1)$ \\
\hline \multicolumn{2}{|l|}{ Type of accommodation } \\
\hline Rented room & $39(36.1)$ \\
\hline Student hostel & $27(25.0)$ \\
\hline Self-owned flat & $23(21.3)$ \\
\hline Rented family flat & $19(17.6)$ \\
\hline Others & I $(0.9)$ \\
\hline \multicolumn{2}{|l|}{ Past medical history } \\
\hline None & $79(73.1)$ \\
\hline Systemic disease (eg, Hypertension, Diabetes Mellitus) & $13(12.0)$ \\
\hline Musculoskeletal disorders (eg, low back pain, neck pain, knee pain) & $7(6.5)$ \\
\hline Depression or Stress & $9(8.3)$ \\
\hline \multicolumn{2}{|l|}{ Where did you stay during the outbreak of COVID 19 pandemic? } \\
\hline Hong Kong & $35(32.4)$ \\
\hline Asia (other than Hong Kong, mainland China, Taiwan, or India) & $23(21.3)$ \\
\hline India & $16(14.8)$ \\
\hline Arab countries (Saudi Arabia and UAE) & $15(13.9)$ \\
\hline African countries (Nigeria and Ghana) & $9(8.3)$ \\
\hline Others & $10(9.3)$ \\
\hline
\end{tabular}


Table 2 Associations Among Sleep Habits, Generalized Anxiety, and Perceived Stress Scores During the Coronavirus (COVID-19) Pandemic

\begin{tabular}{|c|c|c|c|c|c|}
\hline \multirow[t]{2}{*}{$(N=108)$} & \multirow[t]{2}{*}{ Mean } & \multirow[t]{2}{*}{ SD } & \multirow{2}{*}{$\begin{array}{l}\text { Range } \\
\text { Min - Max }\end{array}$} & \multicolumn{2}{|c|}{$\begin{array}{c}\text { Pearson } \\
\text { Correlations }\end{array}$} \\
\hline & & & & GAD-7 & PSS- 10 \\
\hline $\mathrm{SHI}(0-52)$ & 23.1 & 7.3 & $6-41$ & $0.384 *$ & $0.423^{*}$ \\
\hline GAD-7 (0-28) & 9.2 & 6.2 & $0-21$ & & \\
\hline PSS-I0 (0-40) & 21.4 & 4.3 & $9-36$ & $0.601 *$ & - \\
\hline
\end{tabular}

Notes: Data are mean (standard deviation); ${ }^{*}$ Correlation is significant at the 0.01 level (2-tailed); $\mathrm{SHI}=$ Sleep Hygiene Index; GAD = Generalized Anxiety Disorders7 scale; PSS-10 $=$ Perceived stress scale- 10.

respectively during the COVID pandemic. There were significant correlations among sleep hygiene, anxiety, and stress during the COVID-19 pandemic (Table 2). Percentage of poor sleep hygiene score was slightly higher in females compared to males (Figure 2). However, there were no significant differences in SHI scores between genders $(p>0.05)$. While the percentage of moderate levels of generalized anxiety was slightly higher in males than female students, more female students had a severe level of generalized anxiety than their male counterparts (Figure 3). However, there was no statistically significant difference between males and females $(p>0.05)$. Likewise, the percentage of moderate level of perceived stress was higher in males compared to females, although the severe level of perceived stress was equally distributed in both male and female students (Figure 4). However, these differences were statistically insignificant $(\mathrm{p}>0.05)$.

\section{Factors Affecting Generalized Anxiety and Perceived Stress During the COVID Pandemic}

Table 3 summarizes the results of the hierarchical regression analyses regarding the determinants of anxiety levels and perceived stress scores. The determinants explained $29.0 \%$ of the variance in the anxiety levels model $\left(\mathrm{R}^{2}=0.288\right.$ (adjusted $\left.\mathrm{R}^{2}=0.215, \mathrm{~F}(10,107)=3.929, \mathrm{p}=0.000\right)$ ) and $35 \%$ of the variance in the perceived stress model $\left(\mathrm{R}^{2}=0.346\right.$ (adjusted $\left.\mathrm{R}^{2}=0.279, \mathrm{~F}(10,107)=5.136, \mathrm{p}=0.000\right)$ ). When individual determinants of anxiety levels were examined, prior medical history $(\mathrm{B}=1.97, \mathrm{p}=0.001)$ and poor sleep hygiene

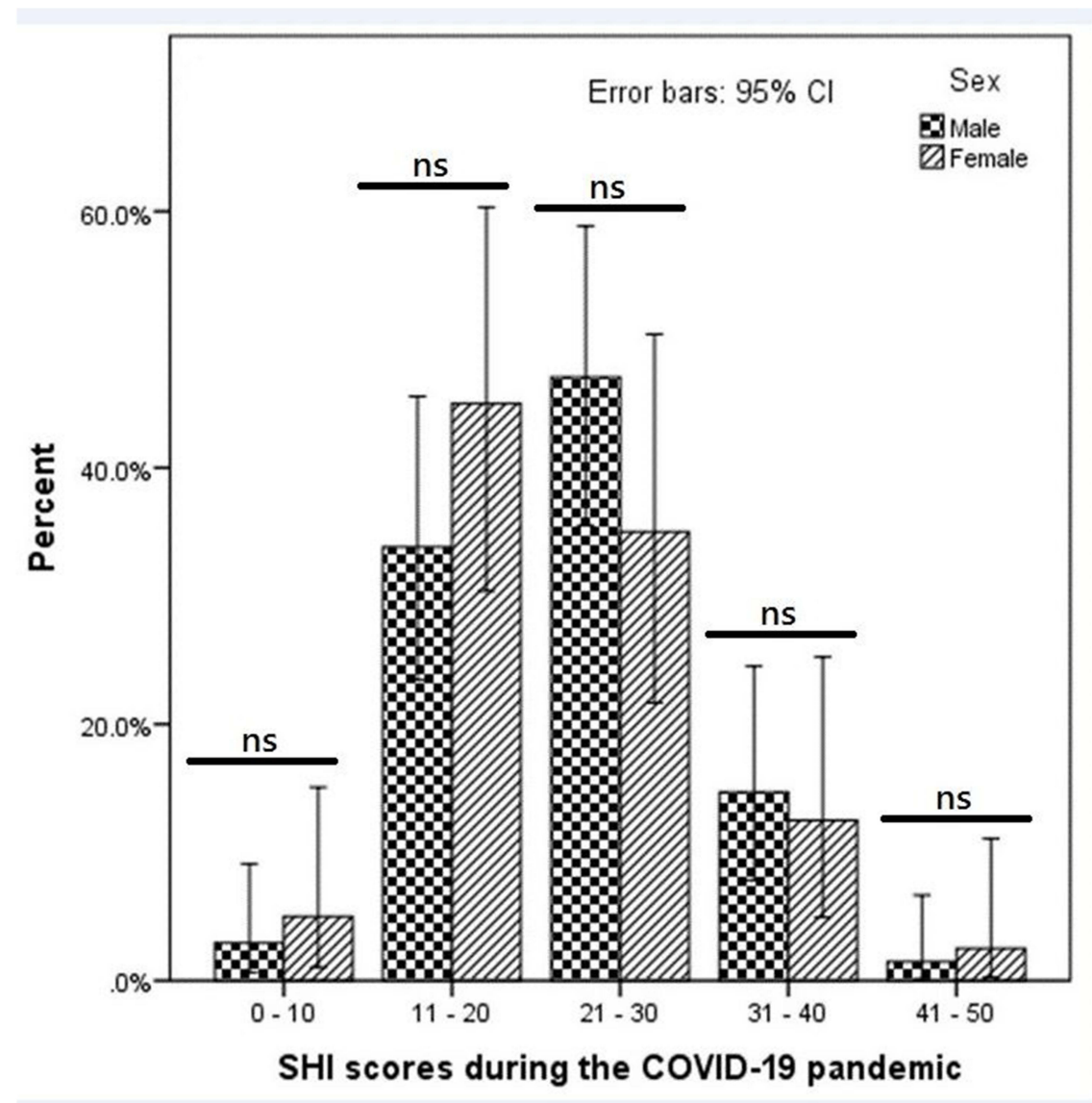

Figure 2 Percentage of poor sleep hygiene scores in males and females during the COVID-19 pandemic. 


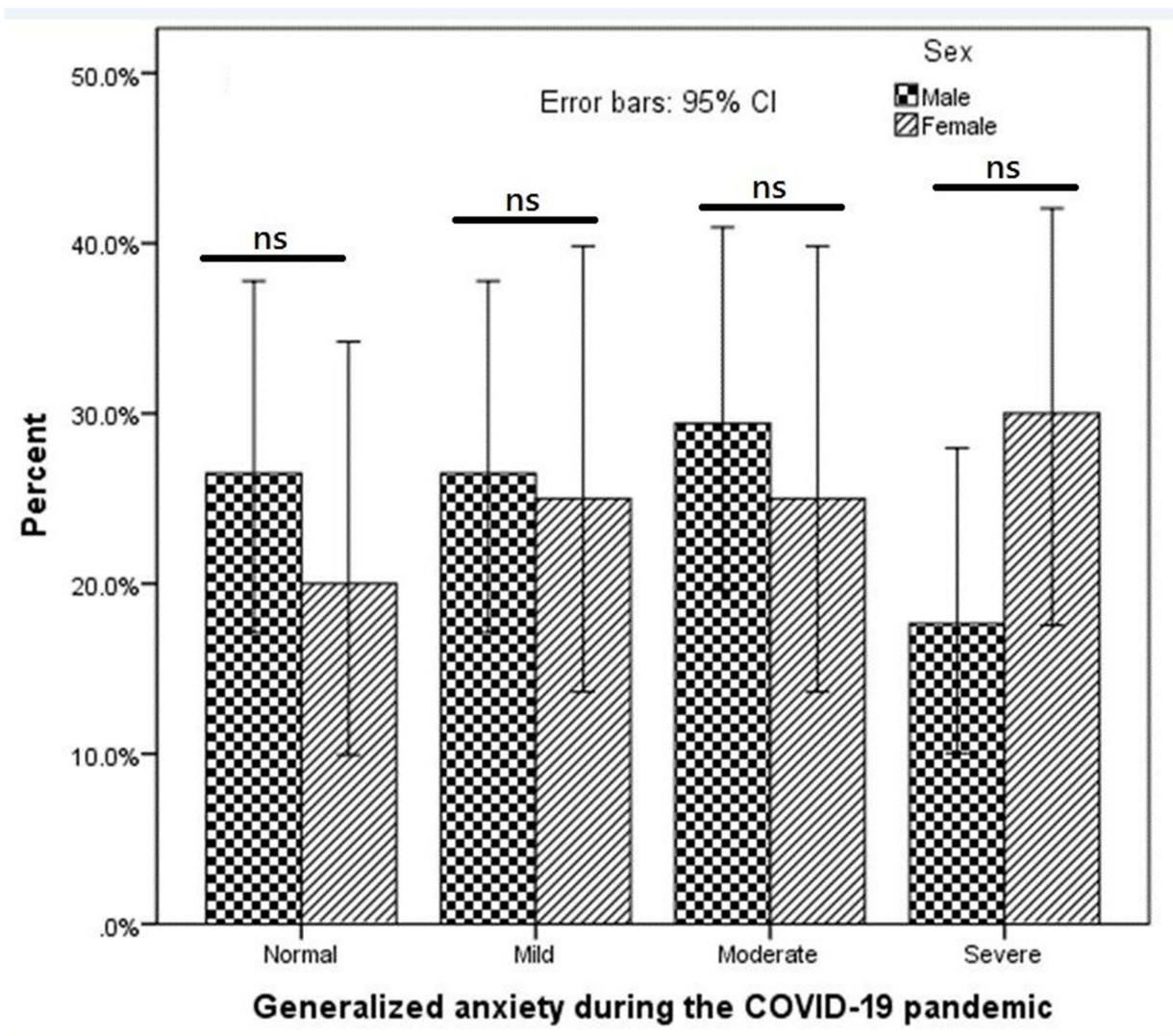

Figure 3 Percentage of anxiety levels in males and females during the COVID-19 pandemic.

$(\mathrm{B}=0.312, \mathrm{p}=0.000)$ were significantly associated with an elevated level of anxiety scores. Likewise, ethnicity $(\mathrm{B}=-0.923, \mathrm{p}=0.003)$, past medical history $(\mathrm{B}=1.112$, $p=0.005)$, and poor sleep hygiene $(B=0.259, p=0.000)$ were significantly associated with the level of perceived stress.

\section{Impact of COVID-19 on Research Outcomes}

Table 4 details the impacts of the COVID-19 pandemic on the research-related outputs. More than one-third of the respondents could hardly concentrate on their research work (eg, writing manuscripts, reading articles, etc.) during the COVID-19 pandemic. More than two-thirds of the respondents reported that they were not able to conduct their research experiments during the COVID-19 pandemic. While $36 \%$ of the respondents anticipated that they could resume normal research activities after $0-3$ or 3-6 months, $19 \%$ of respondents thought it might take up to nine months to return to normal. Regarding the research experiments, one-third of the respondents made little change in their experiment(s) during the outbreak, onefifth of the respondents made some-to-great changes. One- fourth of the participants slightly changed their research topic due to the pandemic, but nearly half of the respondents made little to some modifications in the methods of data collection during the COVID-19 pandemic.

Table 5 illustrates the major concerns of postgraduate research students during the COVID-19 pandemic. The top six concerns of our respondents were: (1) lack of participants for research experiments; (2) fear of exposure to the novel coronavirus from research participants; (3) community transmission; (4) cancellation of international travels that might affect their attachment program; (5) unable to meet the supervisors frequently; and (6) unable to attend any scientific conferences.

\section{Discussion}

This study aimed to evaluate the impacts of the COVID-19 pandemic on sleep hygiene, anxiety levels, perceived stress, and research outcomes among postgraduate research students. Our findings revealed that postgraduate research students had poor sleep habits and increased generalized anxiety and self-perceived stress during the COVID-19 pandemic. The current study discovered an 


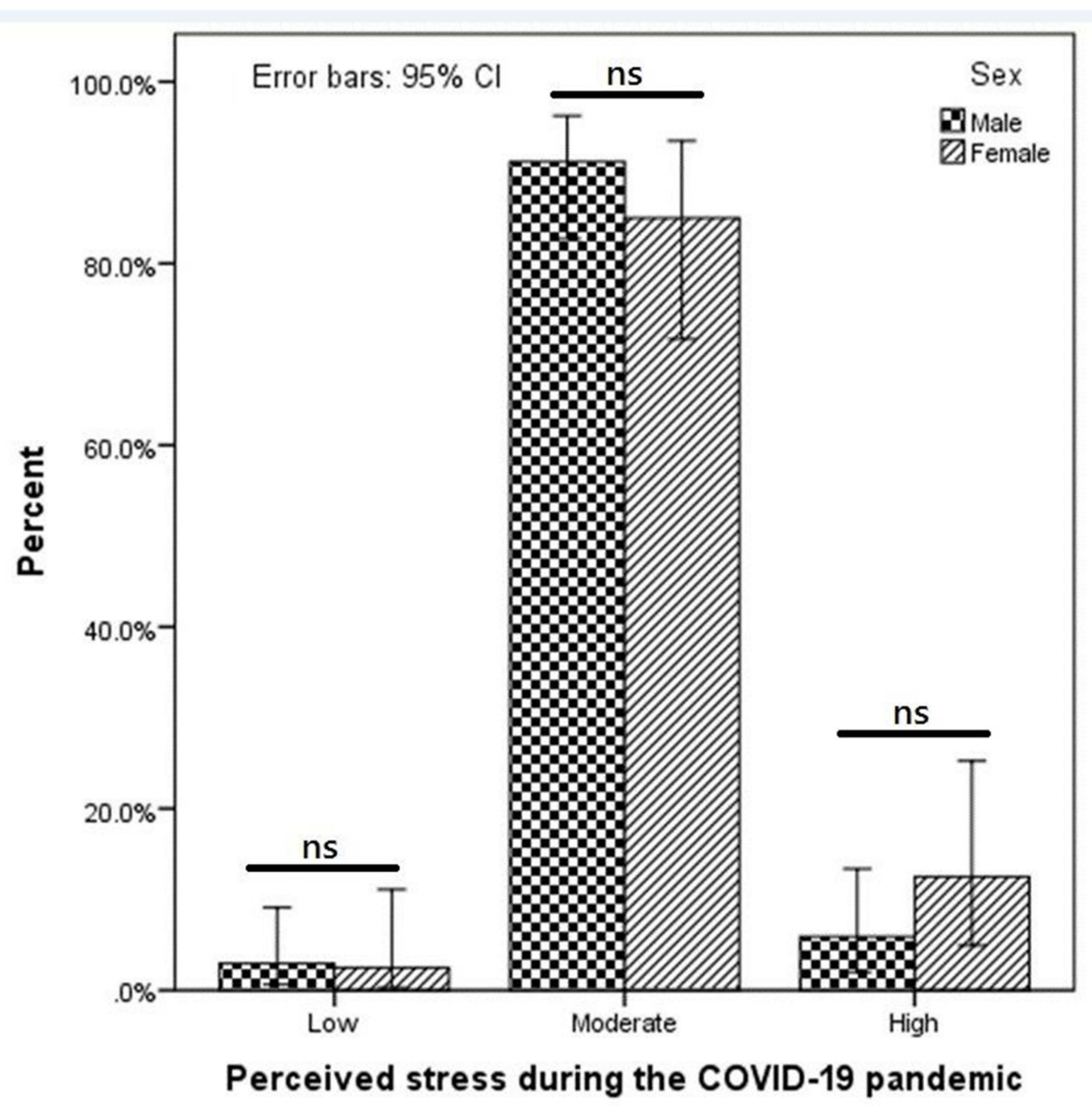

Figure 4 Percentage of perceived stress in males and females during the COVID-19 pandemic.

association between poor sleep hygiene, generalized anxiety, and perceived stress among postgraduate research university students during COVID-19. Various factors such as ethnicity, medical history (eg, systemic disease, musculoskeletal disorders, depression or stress), and poor sleep hygiene were associated with generalized anxiety and perceived stress during the COVID-19 pandemic in postgraduate research students. As hypothesized, COVID19 pandemic also severely affected students' research work (such as difficulty in conducting research experiments and keeping pace or focus on their research), which caused a lot of concerns to postgraduate research students.

\section{Impacts of COVID-19 on Sleep Hygiene}

Our respondents reported poor sleep habits during the outbreak of COVID-19 pandemic, which concurred with research examining the impact of COVID-19 on sleep habits of medical professionals (a higher percentage of poor sleep score has been increased during the COVID19 pandemic). ${ }^{48}$ Similarly, recent studies have found a significantly higher percentage of the general population had poor sleep hygiene during the COVID-19 pandemic. ${ }^{49-52}$ Another study reported poor sleep hygiene scores among African university students prior to the COVID 19 pandemic. $^{53}$ The factors that contribute to poor sleep hygiene in postgraduate research students may be complex (eg, family issues, loneliness etc). ${ }^{54}$ As a result, future research should focus on the factors of poor sleep hygiene among postgraduate students.

\section{Impacts of COVID-19 on Generalized Anxiety and Perceived Stress}

Previous studies have reported heightened levels of anxiety ${ }^{49,55-57}$ and perceived stress ${ }^{5-61}$ among the general population during the epidemic (severe acute respiratory syndrome and Covid-19). Wang et $\mathrm{al}^{62}$ indicated increased anxiety and stress among college students during the COVID-19 pandemic. Similarly, studies in both developed and developing countries showed that undergraduate or postgraduate students had an increased level of anxiety, depression, or stress during the outbreak of COVID-19 pandemic. ${ }^{63-65}$ Up to $48 \%$ of them 
Table 3 Hierarchical Regression Predicting Generalized Anxiety and Perceived Stress During the COVID-19 Pandemic Among Postgraduate Research Students

\begin{tabular}{|c|c|c|c|c|c|c|c|c|}
\hline \multirow[t]{2}{*}{ Variables $(N=108)$} & \multicolumn{4}{|c|}{ Generalized Anxiety } & \multicolumn{4}{|c|}{ Perceived Stress } \\
\hline & $\mathbf{R}^{2}$ & B & $\mathbf{p}$ & $f^{2}$ & $\mathbf{R}^{2}$ & B & $\mathbf{p}$ & $f^{2}$ \\
\hline \multicolumn{9}{|l|}{ Block I } \\
\hline Age & 0.040 & 0.278 & 0.099 & 0.042 & 0.057 & 0.003 & 0.979 & 0.060 \\
\hline Sex & & 2.065 & 0.132 & & & 0.941 & 0.318 & \\
\hline Marital status & & -2.086 & 0.161 & & & -0.763 & 0.455 & \\
\hline Ethnicity & & -0.092 & 0.846 & & & -0.648 & 0.051 & \\
\hline \multicolumn{9}{|l|}{ Block 2} \\
\hline Age & 0.047 & 0.249 & 0.165 & 0.049 & 0.075 & -0.017 & 0.890 & 0.081 \\
\hline Sex & & 2.131 & 0.148 & & & 0.750 & 0.455 & \\
\hline Marital status & & -1.952 & 0.202 & & & -0.611 & 0.559 & \\
\hline Ethnicity & & -0.121 & 0.805 & & & -0.674 & 0.046 & \\
\hline Accommodation & & 0.380 & 0.550 & & & 0.429 & 0.325 & \\
\hline Level of education & & 0.509 & 0.546 & & & 0.135 & 0.816 & \\
\hline Field of research & & 0.045 & 0.928 & & & 0.326 & 0.342 & \\
\hline \multicolumn{9}{|l|}{ Block 3} \\
\hline Age & 0.288 & 0.218 & 0.165 & 0.405 & 0.588 & -0.037 & 0.722 & 1.427 \\
\hline Sex & & 1.937 & 0.136 & & & 0.655 & 0.448 & \\
\hline Marital status & & -0.419 & 0.760 & & & 0.556 & 0.542 & \\
\hline Ethnicity & & -0.417 & 0.357 & & & -0.923 & $0.003 *$ & \\
\hline Accommodation & & 0.729 & 0.202 & & & 0.720 & 0.060 & \\
\hline Level of education & & 0.387 & 0.609 & & & 0.066 & 0.895 & \\
\hline Field of research & & -0.251 & 0.573 & & & 0.143 & 0.630 & \\
\hline Past medical history & & 1.957 & $0.001 *$ & & & 1.112 & $0.005 *$ & \\
\hline Country of stay during the outbreak of COVID 19 & & 0.268 & 0.442 & & & 0.279 & 0.231 & \\
\hline Sleep Hygiene & & 0.312 & $0.000 *$ & & & 0.259 & $0.000 *$ & \\
\hline
\end{tabular}

Notes: ${ }^{*} \mathrm{p}<0.05 ; \mathrm{B}=$ Beta; Effect size $\left(\mathrm{f}^{2}\right)=0.02$ (small), 0.15 (medium), 0.35 (large).

had severe levels of anxiety, depression, or stress. ${ }^{62-65} \mathrm{Up}$ to $50 \%$ of the adults in the UK experienced increased anxiety, depression, or stress due to fear of contracting the virus. ${ }^{51}$ Particularly, health anxiety, which commonly occurs after the outbreak of any pandemic such as COVID-19. ${ }^{66}$ Consequently, people may show unique behaviors such as social withdrawal, excessive hand washing, apprehensive purchasing, and consumption of resources including medications, protective masks, and hand sanitizers. ${ }^{67}$ Teaching and research-related activities have been severely affected due to locked down and social distancing norms during the COVID19 pandemic. $^{63}$ Additionally, most research conferences and attachment programs have been postponed or cancelled to minimize the risk of spreading COVID-19 pandemic. $^{8}$ All these factors may cause increased anxiety levels among postgraduate research students during the COVID-19 pandemic. Furthermore, uncertainty regarding academic and research progression could be a stressor for postgraduate students. ${ }^{68}$
People with higher levels of education were more anxious, depressed, and stressed during the COVID-19 pandemic. Recent studies have found that anxiety and depression levels are related to levels of education during the COVID-19 pandemic. ${ }^{69,70}$ One Chinese study found that higher rates of mental illness among people with a higher level of education might be attributed to their higher self-awareness of their health. ${ }^{71}$ Insufficient understanding of COVID-19, the high fatality rate of infected patients, and worries about its spread are good reasons to feel stressed. ${ }^{72,73}$ Additionally, a low level of physical activity during the lockdown due to COVID-19 can cause more anxiety and stress. ${ }^{74}$ Furthermore, reduced physical activity secondary to social distancing and lockdown may increase the risk of mental health. ${ }^{75}$

While past medical history (eg, systemic disease, depression, or stress) and poor sleep hygiene were significantly associated with increased generalized anxiety disorders, the ethnic origin, past medical history, and poor sleep hygiene 
Table 4 Impacts of the Coronavirus (COVID-19) Pandemic on the Research-Related Outputs

\begin{tabular}{|c|c|}
\hline Research Related Questions $(N=108)$ & $\begin{array}{l}\text { Frequency } \\
\text { (\%) }\end{array}$ \\
\hline $\begin{array}{l}\text { Are you able to concentrate on your research } \\
\text { activities (eg, writing manuscript, reading articles, } \\
\text { etc.) during the COVID-19 pandemic? } \\
\text { No } \\
\text { Minimal } \\
\text { To some extent } \\
\text { To a great extent }\end{array}$ & $\begin{array}{ll}21 & (19.4) \\
24 & (22.2) \\
39 & (36.1) \\
24 & (22.2)\end{array}$ \\
\hline $\begin{array}{l}\text { Are you able to conduct your experiments during the } \\
\text { COVID-I9 pandemic? } \\
\text { No } \\
\text { Minimal } \\
\text { To some extent } \\
\text { To a great extent }\end{array}$ & $\begin{array}{l}51(47.2) \\
29(26.9) \\
21(19.4) \\
7(6.5)\end{array}$ \\
\hline $\begin{array}{l}\text { After how long you think that you will be able to } \\
\text { perform your research activities as normal as before } \\
\text { COVID-I9? } \\
\text { 0-3 months } \\
3-6 \text { months } \\
6-9 \text { months } \\
>\text { one year }\end{array}$ & $\begin{array}{l}39(36.1) \\
39(36.1) \\
21(19.4) \\
9(8.3)\end{array}$ \\
\hline $\begin{array}{l}\text { Have you changed your research experiment(s) (eg, } \\
\text { change to observational) due to COVID-19 } \\
\text { pandemic? } \\
\text { No } \\
\text { Little extent } \\
\text { Some extent } \\
\text { Great extent }\end{array}$ & $\begin{array}{l}47(43.5) \\
37(34.3) \\
17(15.7) \\
7(6.5)\end{array}$ \\
\hline $\begin{array}{l}\text { Have you changed your research topic due to the } \\
\text { COVID-19 pandemic? } \\
\text { No } \\
\text { Little extent } \\
\text { Some extent } \\
\text { Complete changed }\end{array}$ & $\begin{array}{l}76(70.4) \\
20(18.5) \\
8(7.4) \\
4(3.7)\end{array}$ \\
\hline $\begin{array}{l}\text { Have you modified your ways of data collection due } \\
\text { to the COVID-19 pandemic? } \\
\text { No } \\
\text { Little extent } \\
\text { Some extent } \\
\text { Great extent }\end{array}$ & $\begin{array}{l}44(40.7) \\
27(25.0) \\
26(24.1) \\
\text { II }(10.2)\end{array}$ \\
\hline
\end{tabular}

were significantly related to increased perceived stress among postgraduate research students. A recent review revealed that patients with a history of anxiety demonstrated increased generalized anxiety disorders. ${ }^{66}$ A recent study from Australia suggests that individuals with a history of mental health problems (eg, anxiety or stress) showed higher anxiety or stress compared to those who do not have a history of mental illness. ${ }^{76}$ Since we did not collect the nature, severity, and type of stress or anxiety, it was difficult to evaluate whether these students had higher levels of anxiety or stress before the COVID-19 pandemic, or whether stress or anxiety increased due to COVID-19 pandemic as a result of social distancing, reduced family support, or fear of getting infected. ${ }^{77}$ More recently, Manzar et al ${ }^{78}$ have discovered a link between insufficient sleep hygiene habits and anxiety levels among university students. In contrast to current findings, a past study conducted in Malaysia found no significant correlation between ethnicity and anxiety, depression, or stress in university students. ${ }^{79}$

Similar to current findings, previous studies have reported no association between gender of students and anxiety or stress. ${ }^{79-82}$ In contrast, other studies have suggested an association between some socio-demographic variables (including age and gender) and levels of anxiety. ${ }^{55,83}$ Similarly, female students in Egyptian universities were prone to develop anxiety and less likely to suffer stress than their male counterparts. ${ }^{84}$

\section{Impacts of COVID-19 Pandemic on Research Outputs of Postgraduate Research Students}

Findings of our study revealed negative impacts of COVID19 on the research outputs. Likewise, previous studies found a few impacts of COVID-19 on academic activities including difficulty in concentrating, lack of an interactive learning environment, and lack of motivation among undergraduate or graduate students. ${ }^{85-87}$ The present study indicates that fear of getting infected with coronavirus was one of the major concerns of postgraduate research students during the COVID-19 pandemic. Likewise, previous studies in college/university students indicated that most of their respondents were worried they might get infected with COVID-19 disease. ${ }^{62,88}$ They also indicated that COVID19 pandemic affected their daily academic routine. ${ }^{88}$ Additionally, travel and social restrictions during the pandemic significantly affected scientific research globally. ${ }^{89}$

\section{Associations Between Poor Sleep Habit and Perceived Stress or Generalized Anxiety}

This study found the positive correlations between poor sleep habit and perceived stress or generalized anxiety among 
Table 5 Major Concerns of Postgraduate Research Students During the Coronavirus (COVID-19) Pandemic

\begin{tabular}{|l|l|}
\hline Questions Related to Major Concerns (N = 108) & *Frequency (\%) \\
\hline Lack of participants for research experiments & $47(43.5)$ \\
Fear of exposing to the novel coronavirus from the participants & 45 (4I.7) \\
Lack of required equipment supply due to COVID-19 & $15(13.9)$ \\
Increase research cost & $15(13.9)$ \\
Increase risk of contracting the virus during travel for data collection (eg, Community transmission) & $38(35.2)$ \\
Lack of resources for the thesis writing (eg, Library, internet, printing) & $24(22.2)$ \\
Unable to meet the deadlines of thesis submission & $25(23.1)$ \\
Running out of the funding support & $15(13.9)$ \\
Unable to meet the supervisors frequently & 3 (28.7) \\
Unable to complete the required course work as planned & 2 (I9.4) \\
Unable to attend any scientific conferences & $30(27.8)$ \\
International travels are cancelled affecting attachment program & 34 (3I.5) \\
\hline
\end{tabular}

Note: *Multiple responses.

postgraduate research students in Hong Kong. While no study has investigated the associations between sleep habits and perceived stress or anxiety levels among postgraduate research students during the COVID-19 pandemic, a few past studies published before the COVID-19 pandemic found a significant association between poor sleep habits and poor mental health among college students. ${ }^{90-92}$ For instance, a previous cross-sectional survey discovered that sleeprelated problems including daytime sleeping and impaired sleep quality was associated with an increased risk of common mental disorders among college students. ${ }^{90}$ Another study found that college students who had sleep disturbances had a higher anxiety symptom and a greater loss of cognitive and physical function than students who did not have sleep disturbances. ${ }^{91}$ Similarly, Zhang et $\mathrm{al}^{92}$ discovered a link between poor sleep quality and an elevated incidence of anxiety and depression in collegiate nursing students. They also discovered that perceived stress acts as a mediator between sleep quality and anxiety. ${ }^{92}$ As a result, effective interventions are required to improve sleep hygiene behavior and mental health in postgraduate research students.

\section{Strength and Limitations}

This study had several strengths. First, this is the only study which captured the perception of sleep hygiene, generalized anxiety, and perceived stress during the COVID-19 pandemic among postgraduate research students. Second, the current study used standardized questionnaires (eg, SHI, GAD-7, and PSS-10) to assess sleep hygiene, generalized anxiety, and perceived stress in postgraduate research students. Finally, the impacts of COVID-19 on research-related works and major concerns of postgraduate research students during the COVID-19 pandemic were highlighted.

Nonetheless, there are several limitations that should be acknowledged. First, this study failed to identify sociodemographic predictors of sleep hygiene, generalized anxiety, and perceived stress due to the small sample size. Second, since the current study was designed as a cross-sectional questionnaire-based survey, it could not establish a causal relationship. Third, this study adopted convenience sampling via an online platform, which might introduce a selection bias. Fourth, as the current study relied on self-reported data, it might be affected by participants' interpretations of the question items or their proclivity to report their emotions in particular ways. Finally, the participants of this study were all postgraduate research students studying at Hong Kong universities, which may limit the generalizability of this study to students studying in other countries.

\section{Implications}

Given the high prevalence of stress and anxiety, as well as poor sleep behavior among postgraduate research students during the pandemic, universities should take imminent actions to identify students at risk of mental health issues, and provide proper education to lower the risk of mental health and sleep-related problems among postgraduate students. Specifically, universities may reach out to postgraduate students by emails or through academic supervisors to identify students who need imminent financial or emotional supports. Teachers or academic supervisors should also pay more attention to students with known depression and/or other psychological problems and 
provide appropriate assistance, if necessary. However, if teachers/supervisors notice that a student's psychological problems are severe, a prompt referral to university counselling services or health services is warranted to ensure that the student can receive timely professional consultations and treatments. In addition to identifying high risk cases, regular online webinars/workshops on mental health management and sleep hygiene should be organized to empower postgraduate students in managing their psychological distress and sleep problems during the pandemic. New online promotion (such as games, competitions, and plays) and educational activities (eg, videos and articles) can be launched to engage students, increase their awareness of these issues, and provide them with proper coping methods. These approaches together with adequate counseling services for postgraduate students during and after the COVID-19 outbreak can help students manage their stress and develop effective coping strategies. Furthermore, future research is warranted to evaluate the long-term impacts of COVID-19 on anxiety, stress, sleep, and academic performance of postgraduate students so that universities can better prepare for similar pandemics in the future.

\section{Conclusion}

Postgraduate research students had poor sleep hygiene, moderate-to-severe anxiety levels, and perceived stress during the COVID-19 pandemic in Hong Kong. The sleep hygiene behaviors, generalized anxiety, and perceived stress were high during the COVID-19 pandemic among postgraduate research students. This study discovered positive associations between poor sleep habits and reported stress or generalized anxiety among postgraduate research students. Postgraduate research students' anxiety levels and perceived stress during the COVID-19 pandemic were shown to be connected with characteristics such as ethnicity, medical history (eg, systemic disease, musculoskeletal diseases, depression or stress), and poor sleep hygiene. The present study highlights that postgraduate research students may be prone to poor sleep hygiene, high anxiety levels, or perceived stress during the current pandemic. Longitudinal studies are warranted to explore the long-term predictors of poor sleep hygiene, anxiety levels, or perceived stress over time. The findings show that it is imperative to consider the numerous facets of mental health (ie, anxiety levels and perceived stress) and the multifaceted links to sleep in university students. Since the length and severity of the outbreak are expected to be longer, future studies are warranted to develop and implement strategies to improve sleep hygiene, anxiety levels, and perceived stress in postgraduate research students.

\section{Acknowledgments}

The authors are grateful to the Deanship of Scientific Research, King Saud University for funding through Vice Deanship of Scientific Research Chairs.

\section{Disclosure}

The authors report no conflicts of interest in this publication.

\section{References}

1. Jebril N. World Health Organization declared a pandemic public health menace: a systematic review of the coronavirus disease 2019 "COVID19", up to 26th March 2020. Available at SSRN 3566298. 2020.

2. WHO. Coronavirus disease (COVID-19) outbreak situation. Available from: https://covid19.who.int/. Accessed October 30, 2021.

3. Wilder-Smith A, Freedman DO. Isolation, quarantine, social distancing and community containment: pivotal role for old-style public health measures in the novel coronavirus (2019-nCoV) outbreak. $J$ Travel Med. 2020;27(2):1-4. doi:10.1093/jtm/taaa020

4. Wilder-Smith A, Chiew CJ, Lee VJ. Can we contain the COVID-19 outbreak with the same measures as for SARS? Lancet Infect Dis. 2020;20(5):e102-e7. doi:10.1016/S1473-3099(20)30129-8

5. Cowling BJ, Ali ST, $\mathrm{Ng} \mathrm{TW}$, et al. Impact assessment of non-pharmaceutical interventions against coronavirus disease 2019 and influenza in Hong Kong: an observational study. Lancet Public Health. 2020;5(5):e279-e88. doi:10.1016/S2468-2667(20)30090-6

6. Aydemir D, Ulusu NN. Identifying and solving scientific problems in the medicine: key to become a competent scientist. Turk J Biochem. 2020;45(2). doi:10.1515/tjb-2018-0357

7. Aydemir D, Ulusu NN. Commentary: challenges for PhD students during COVID-19 pandemic: turning crisis into an opportunity. Biochem Mol Biol Educ. 2020;48(5):428-429. doi:10.1002/ bmb. 21351

8. Marinoni G, Van't Land H, Jensen T. The impact of Covid-19 on higher education around the world. IAU global survey report; 2020. Available from: https://www.iau-aiu.net/IMG/pdf/iau_covid19_and he_survey_report_final_may_2020.pdf. Accessed October 30, 2021.

9. Offerdahl EG, Momsen JL, Osgood M. Commentary: PhDs in biochemistry education - 5 years later. Biochem Mol Biol Educ. 2014;42 (2):103-105. doi:10.1002/bmb.20768

10. Ratcliff R, Van Dongen HP. Sleep deprivation affects multiple distinct cognitive processes. Psychon Bull Rev. 2009;16(4):742-751. doi:10.3758/PBR.16.4.742

11. Giri P, Baviskar M, Phalke D. Study of sleep habits and sleep problems among medical students of Pravara Institute of Medical Sciences Loni, Western Maharashtra, India. Ann Med Health Sci Res. 2013;3(1):51-54. doi:10.4103/2141-9248.109488

12. Ahrberg K, Dresler M, Niedermaier S, Steiger A, Genzel L. The interaction between sleep quality and academic performance. J Psychiatr Res. 2012;46(12):1618-1622. doi:10.1016/j.jpsychires.20 12.09 .008

13. Ibarra-Coronado EG, Pantaleón-Martínez AM, Velazquéz-Moctezuma J, et al. The bidirectional relationship between sleep and immunity against infections. J Immunol Res. 2015;2015:678164. 
14. Peach H, Gaultney JF, Gray DD. Sleep hygiene and sleep quality as predictors of positive and negative dimensions of mental health in college students. Cogent Psychol. 2016;3(1):1168768. doi:10.1080/ 23311908.2016.1168768

15. McCrae CS, Dzierzewski JM, Kay DB. Treatment of late-life insomnia. Sleep Med Clin. 2009;4(4):593-604. doi:10.1016/j. jsmc.2009.07.006

16. Perlis ML, Jungquist C, Smith MT, Posner D. Cognitive Behavioral Treatment of Insomnia: A Session-By-Session Guide. Springer Science \& Business Media; 2006.

17. Bathija GV, Sushma H. A cross sectional study to assess the sleep hygiene among the post graduates of KIMS, Hubballi. Int J Commun Med Public Health. 2019;6(4):1645. doi:10.18203/2394-6040. ijcmph20191399

18. Brick CA, Seely DL, Palermo TM. Association between sleep hygiene and sleep quality in medical students. Behav Sleep Med. 2010;8(2):113-121. doi:10.1080/15402001003622925

19. Al-Kandari S, Alsalem A, Al-Mutairi S, Al-Lumai D, Dawoud A, Moussa M. Association between sleep hygiene awareness and practice with sleep quality among Kuwait University students. Sleep Health. 2017;3(5):342-347. doi:10.1016/j.sleh.2017.06.004

20. Suen L, Tam W, Hon K. Association of sleep hygiene-related factors and sleep quality among university students in Hong Kong. Hong Kong Med J. 2010;16(3):180-185.

21. Vanderlind WM, Beevers CG, Sherman SM, et al. Sleep and sadness: exploring the relation among sleep, cognitive control, and depressive symptoms in young adults. Sleep Med. 2014;15(1):144-149. doi:10.1016/j.sleep.2013.10.006

22. Short MA, Gradisar M, Lack LC, Wright HR. The impact of sleep on adolescent depressed mood, alertness and academic performance. J Adolesc. 2013;36(6):1025-1033. doi:10.1016/j.adolescence.20 13.08.007

23. Menon B, Karishma HP, Mamatha IV. Sleep quality and health complaints among nursing students. Ann Indian Acad Neurol. 2015;18(3):363. doi:10.4103/0972-2327.157252

24. Forbes EE, Bertocci MA, Gregory AM, et al. Objective sleep in pediatric anxiety disorders and major depressive disorder. $\mathrm{J} \mathrm{Am}$ Acad Child Adolesc Psychiatry. 2008;47(2):148-155. doi:10.1097/ chi.0b013e31815cd9bc

25. Storch EA, Murphy TK, Lack CW, Geffken GR, Jacob ML, Goodman WK. Sleep-related problems in pediatric obsessive-compulsive disorder. $J$ Anxiety Disord. 2008;22 (5):877-885. doi:10.1016/j.janxdis.2007.09.003

26. Callender J, Fagin J, Jenkins G, Lester J, Smith E. Mental Health of Students in Higher Education. London: Royal College of Psychiatrists; 2011.

27. Jansson M, Linton SJ. The development of insomnia within the first year: a focus on worry. $\mathrm{Br} J$ Health Psychol. 2006;11 (3):501-511. doi:10.1348/135910705X57412

28. Morphy H, Dunn KM, Lewis M, Boardman HF, Croft PR. Epidemiology of insomnia: a longitudinal study in a UK population. Sleep. 2007;30(3):274-280.

29. Jansson-Fröjmark M, Lindblom K. A bidirectional relationship between anxiety and depression, and insomnia? A prospective study in the general population. J Psychosom Res. 2008;64(4):443-449. doi:10.1016/j.jpsychores.2007.10.016

30. Johnson EO, Roth T, Breslau N. The association of insomnia with anxiety disorders and depression: exploration of the direction of risk. J Psychiatr Res. 2006;40(8):700-708. doi:10.1016/j. jpsychires.2006.07.008

31. Monti JM, Monti D. Sleep in schizophrenia patients and the effects of antipsychotic drugs. Sleep Med Rev. 2004;8(2):133-148. doi:10.1016/ S1087-0792(02)00158-2

32. Murphy RJ, Gray SA, Sterling G, Reeves K, DuCette J. A comparative study of professional student stress. J Dent Educ. 2009;73(3):328-337. doi:10.1002/j.0022-0337.2009.73.3.tb04705.x
33. D'silva P, Palatty PL, D'souza O, Chandran SK, Baliga MS. Psychological stress in Northeast Indian students pursuing their higher studies in Mangalore. Indian J Soc Psychiatry. 2020;36 (3):214. doi:10.4103/ijsp.ijsp 9619

34. Lee Smith LJ, Trott M, Yakkundi A, et al. The association between screen time and mental health during COVID-19: a cross sectional study. Psychiatry Res. 2020;292:113333. doi:10.1016/j. psychres.2020.113333

35. Mastin DF, Bryson J, Corwyn R. Assessment of sleep hygiene using the Sleep Hygiene Index. J Behav Med. 2006;29(3):223-227. doi:10.1007/s10865-006-9047-6

36. Spitzer RL, Kroenke K, Williams JB, Löwe B. A brief measure for assessing generalized anxiety disorder: the GAD-7. Arch Intern Med. 2006;166(10):1092-1097. doi:10.1001/archinte.166.10.1092

37. Cohen S, Kamarck T, Mermelstein R, Global A. Measure of perceived stress. J Health Soc Behav. 1983;24(4):385-396. doi:10.2307/ 2136404

38. Chan LL, Wong AY, Wang MH. Associations between sport participation and knee symptoms: a cross-sectional study involving 3053 undergraduate students. BMC Sports Sci Med Rehabil. 2020;12 (1):1-8. doi:10.1186/s13102-020-00169-w

39. Chan LL, Wong AY, Wang MH, Cheung K, Samartzis D. The prevalence of neck pain and associated risk factors among undergraduate students: a large-scale cross-sectional study. Int $J$ Ind Ergon. 2020;76:102934. doi:10.1016/j.ergon.2020.102934

40. Weess HG. Diagnostics of sleep disorders. Verhaltenstherapie. 2005;15(4):220-233. doi:10.1159/000089490

41. Anwer S, Alghadir A, Manzar MD, Noohu MM, Salahuddin M, Li H. Psychometric analysis of the sleep hygiene index and correlation with stress and anxiety among Saudi University students. Nat Sci Sleep. 2019;11:325-332. doi:10.2147/NSS.S222440

42. Doi S, Ito M, Takebayashi Y, Muramatsu K, Horikoshi M. Factorial validity and invariance of the 7-item generalized anxiety disorder scale (GAD-7) among populations with and without self-reported psychiatric diagnostic status. Front Psychol. 2018;9:1741. doi:10.3389/fpsyg.2018.01741

43. Alghadir A, Manzar MD, Anwer S, Albougami A, Salahuddin M. Psychometric properties of the generalized anxiety disorder scale among Saudi University male students. Neuropsychiatr Dis Treat. 2020;16:1427-1432. doi:10.2147/NDT.S246526

44. Manzar MD, Salahuddin M, Peter S, et al. Psychometric properties of the perceived stress scale in Ethiopian university students. $B M C$ Public Health. 2019;19(1):1-8. doi:10.1186/s12889-018-6310-z

45. Lee EH. Review of the psychometric evidence of the perceived stress scale. Asian Nurs Res. 2012;6(4):121-127. doi:10.1016/j. anr.2012.08.004

46. Alyoubi A, Halstead EJ, Zambelli Z, Dimitriou D. The impact of the COVID-19 pandemic on students' mental health and sleep in Saudi Arabia. Int $J$ Environ Res Public Health. 2021;18(17):9344. doi:10.3390/ijerph18179344

47. Soper DS. A-priori sample size calculator for multiple regression [Software]; 2021. Available from: https://www.danielsoper.com/stat calc. Accessed October 30, 2021.

48. Ferini-Strambi L, Zucconi M, Casoni F, Salsone M. COVID-19 and sleep in medical staff: reflections, clinical evidences, and perspectives. Curr Treat Option N. 2020;22(10):1-6.

49. Huang YE, Zhao N. Generalized anxiety disorder, depressive symptoms and sleep quality during COVID-19 outbreak in China: a web-based cross-sectional survey. Psychiatry Res. 2020;288:112954. doi:10.1016/j.psychres.2020.112954

50. Altena E, Baglioni C, Espie CA, et al. Dealing with sleep problems during home confinement due to the COVID-19 outbreak: practical recommendations from a task force of the European CBT-I academy. J Sleep Res. 2020;29(4):e13052. doi:10.1111/jsr.13052

51. Duffy B. Life Under Lockdown: Coronavirus in the UK. Kings College London: The Policy Institute; 2020. 
52. Innocenti P, Puzella A, Mogavero MP, Bruni O, Ferri R. Letter to editor: CoVID-19 pandemic and sleep disorders-a web survey in Italy. Neurolog Sci. 2020;41(8):2021-2022. doi:10.1007/s10072020-04523-1

53. Reid A, Baker FC. Perceived sleep quality and sleepiness in South African university students. S Afr J Psychol. 2008;38(2):287-303. doi: $10.1177 / 008124630803800203$

54. Smolicz JJ, Secombe MJ, Hudson DM. Family collectivism and minority languages as core values of culture among ethnic groups in Australia. J Multiling Multicultural Dev. 2001;22(2):152-172. doi:10.1080/01434630108666430

55. Li QM, Miao YD, Zeng X, Tarimo CS, Wu CP, Wu J. Prevalence and factors for anxiety during the coronavirus disease 2019 (COVID-19) epidemic among the teachers in China. $J$ Affect Disorders. 2020;277:153-158. doi:10.1016/j.jad.2020.08.017

56. Qiu JY, Shen B, Zhao M, Wang Z, Xie B, Xu YF. A nationwide survey of psychological distress among Chinese people in the COVID-19 epidemic: implications and policy recommendations. Gen Psychiat. 2020;33(2):e100213. doi:10.1136/gpsych-2020100213

57. Bauerle A, Teufel M, Musche V, et al. Increased generalized anxiety, depression and distress during the COVID-19 pandemic: a cross-sectional study in Germany. $J$ Public Health (Bangkok). 2020;42(4):672-678. doi:10.1093/pubmed/fdaa106

58. Liu S, Yang LL, Zhang CX, et al. Online mental health services in China during the COVID-19 outbreak. Lancet Psychiat. 2020;7(4): E17-E18. doi:10.1016/S2215-0366(20)30077-8

59. Wang CY, Pan RY, Wan XY, et al. Immediate psychological responses and associated factors during the initial stage of the 2019 Coronavirus disease (COVID-19) epidemic among the general population in China. Int J Environ Res Public Health. 2020;17(5):1729. doi:10.3390/ijerph17051729

60. Cao WJ, Fang ZW, Hou GQ, et al. The psychological impact of the COVID-19 epidemic on college students in China. Psychiatry Res. 2020;287:112934. doi:10.1016/j.psychres.2020.112934

61. Moccia L, Janiri D, Pepe M, et al. Affective temperament, attachment style, and the psychological impact of the COVID-19 outbreak: an early report on the Italian general population. Brain Behav Immun. 2020;87:75-79. doi:10.1016/j.bbi.2020.04.048

62. Wang XM, Hegde S, Son C, Keller B, Smith A, Sasangohar F. Investigating mental health of US college students during the COVID-19 pandemic: cross-sectional survey study. $J$ Med Internet Res. 2020;22(9):e22817. doi:10.2196/22817

63. Khan AH, Sultana MS, Hossain S, Hasan MT, Ahmed HU, Sikder MT. The impact of COVID-19 pandemic on mental health \& wellbeing among home-quarantined Bangladeshi students: a crosssectional pilot study. $J$ Affect Disorders. 2020;277:121-128. doi:10.1016/j.jad.2020.07.135

64. Wang CY, Zhao H. The impact of COVID-19 on anxiety in Chinese University students. Front Psychol. 2020;11:1168. doi:10.3389/ fpsyg.2020.01168

65. Asmundson GJG, Taylor S. How health anxiety influences responses to viral outbreaks like COVID-19: what all decision-makers, health authorities, and health care professionals need to know. J Anxiety Disord. 2020;71:102211. doi:10.1016/j.janxdis.2020.102211

66. Pedrosa AL, Bitencourt L, Froes ACF, et al. Emotional, behavioral, and psychological impact of the COVID-19 pandemic. Front Psychol. 2020;11:566212. doi:10.3389/fpsyg.2020.566212

67. Asmundson GJG, Taylor S. Coronaphobia: fear and the 2019-nCoV outbreak. $J$ Anxiety Disord. 2020;70:102196. doi:10.1016/j. janxdis.2020.102196

68. Roy D, Tripathy S, Kar SK, Sharma N, Verma SK, Kaushal V. Study of knowledge, attitude, anxiety \& perceived mental healthcare need in Indian population during COVID-19 pandemic. Asian J Psychiatr. 2020;51:102083. doi:10.1016/j.ajp.2020.102083
69. Moghanibashi-Mansourieh A. Assessing the anxiety level of Iranian general population during COVID-19 outbreak. Asian J Psychiatr. 2020;51:102076. doi:10.1016/j.ajp.2020.102076

70. Wang Y, Di Y, Ye J, Wei W. Study on the public psychological states and its related factors during the outbreak of coronavirus disease 2019 (COVID-19) in some regions of China. Psychol Health Med. 2021;26(1):13-22. doi:10.1080/13548506.2020.1746817

71. Zhang Y, Ma ZF. Impact of the COVID-19 pandemic on mental health and quality of life among local residents in Liaoning Province, China: a cross-sectional study. Int J Environ Res Public Health. 2020;17(7):2381. doi:10.3390/ijerph17072381

72. Banerjee D. The COVID-19 outbreak: crucial role the psychiatrists can play. Asian J Psychiatr. 2020;50:102014. doi:10.1016/j. ajp.2020.102014

73. World Health Organization. Mental Health and Psychosocial Considerations During the COVID-19 Outbreak, 18 March 2020. Geneva: World Health Organization;2020. Contract No.: WHO/2019nCoV/MentalHealth/2020.1.

74. Puccinelli PJ, da Costa TS, Seffrin A, et al. Reduced level of physical activity during COVID-19 pandemic is associated with depression and anxiety levels: an internet-based survey. BMC Public Health. 2021;21(1):1.

75. Woods JA, Hutchinson NT, Powers SK, et al. The COVID-19 pandemic and physical activity. Sports Med Health Sci. 2020;2(2):55-64. doi:10.1016/j.smhs.2020.05.006

76. Newby JM, O'Moore K, Tang S, Christensen H, Faasse K. Acute mental health responses during the COVID-19 pandemic in Australia. PLoS One. 2020;15(7):e0236562. doi:10.1371/journal.pone.0236562

77. Holmes EA, O'Connor RC, Perry VH, et al. Multidisciplinary research priorities for the COVID-19 pandemic: a call for action for mental health science. Lancet Psychiat. 2020;7(6):547-560. doi:10.1016/S2215-0366(20)30168-1

78. Manzar MD, Alghadir AH, Khan M, et al. Anxiety symptoms are associated with higher psychological stress, poor sleep, and inadequate sleep hygiene in collegiate young adults - a cross-sectional study. Front Psychiatr. 2021;12. doi:10.3389/fpsyt.2021.677136

79. Shamsuddin K, Fadzil F, Ismail WSW, et al. Correlates of depression, anxiety and stress among Malaysian university students. Asian J Psychiatr. 2013;6(4):318-323. doi:10.1016/j.ajp.2013.01.014

80. Islam MA, Barna SD, Raihan H, Khan MNA, Hossain MT. Depression and anxiety among university students during the COVID-19 pandemic in Bangladesh: a web-based cross-sectional survey. PLoS One. 2020;15(8):e238162. doi:10.1371/journal. pone. 0238162

81. Alim SA, Rabbani MG, Karim E, Mullick MSI, Al Mamun A, Khan MZR. Assessment of depression, anxiety and stress among first year MBBS students of a public medical college, Bangladesh. Bangla J Psychiatr. 2015;29(1):23-29. doi:10.3329/bjpsy. v29i1.32748

82. Tayefi B, Eftekhar M, Tayefi M, et al. Prevalence and socio-demographic correlates of mental health problems among Iranian health sciences students. Acad Psychiatr. 2020;44(1):73-77. doi:10.1007/s40596-019-01121-y

83. Lejtzen N, Sundquist J, Sundquist K, Li XJ. Depression and anxiety in Swedish primary health care: prevalence, incidence, and risk factors. Eur Arch Psy Clin N. 2014;264(3):235-245.

84. Wolf MR, Rosenstock JB. Inadequate sleep and exercise associated with burnout and depression among medical students. Acad Psychiatr. 2017;41(2):174-179. doi:10.1007/s40596-016-0526-y

85. Son C, Hegde S, Smith A, Wang XM, Sasangohao F. Effects of COVID-19 on college students' mental health in the United States: interview survey study. J Med Internet Res. 2020;22(9):e21279. doi:10.2196/21279

86. Martin JM. Stigma and student mental health in higher education. High Educ Res Dev. 2010;29(3):259-274. doi:10.1080/ 07294360903470969 
87. Kecojevic A, Basch CH, Sullivan M, Davi NK. The impact of the COVID-19 epidemic on mental health of undergraduate students in New Jersey, cross-sectional study. PLoS One. 2020;15(9):e0239696. doi:10.1371/journal.pone. 0239696

88. Olaimat AN, Aolymat I, Elsahoryi N, Shahbaz HM, Holley RA. Attitudes, anxiety, and behavioral practices regarding COVID-19 among university students in Jordan: a cross-sectional study. $\mathrm{Am}$ J Trop Med Hyg. 2020;103(3):1177-1183. doi:10.4269/ajtmh.20-0418

89. Harper L, Kalfa N, Beckers G, et al. The impact of COVID-19 on research. $J$ Pediatr Urol. 2020;16(5):715. doi:10.1016/j. jpurol.2020.07.002
90. Byrd KL, Gelaye B, Tadesse MG, Williams MA, Lemma S, Berhane Y. Sleep disturbances and common mental disorders in college students. Health Behav Policy Rev. 2014;1(3):229-237. doi:10.14485/HBPR.1.3.7

91. Nyer M, Farabaugh A, Fehling K, et al. Relationship between sleep disturbance and depression, anxiety, and functioning in college students. Depress Anxiety. 2013;30(9):873-880. doi:10.1002/da.22064

92. Zhang Y, Peters A, Chen G. Perceived stress mediates the associations between sleep quality and symptoms of anxiety and depression among college nursing students. Int J Nurs Educ Scholarsh. 2018;15 (1):1-9. doi:10.1515/ijnes-2017-0020

\section{Publish your work in this journal}

The Journal of Multidisciplinary Healthcare is an international, peerreviewed open-access journal that aims to represent and publish research in healthcare areas delivered by practitioners of different disciplines. This includes studies and reviews conducted by multidisciplinary teams as well as research which evaluates the results or conduct of such teams or healthcare processes in general. The journal covers a very wide range of areas and welcomes submissions from practitioners at all levels, from all over the world. The manuscript management system is completely online and includes a very quick and fair peer-review system. Visit http://www.dovepress.com/testimonials. php to read real quotes from published authors. 